\title{
Clinical Impact and Prognosis of Pulmonary Hypertension after Transcatheter Aortic Valve Implantation
}

\author{
Green Lisa ${ }^{1 *}$, Rioufol $\mathbf{G}^{1,2}$, Vergnat $\mathrm{M}^{3}$, Obadia $\mathrm{JF}^{2,3}$, Saroul $\mathrm{C}^{3}$, Gevigney GDD ${ }^{1}$, Cudraz EB ${ }^{1}$, CroisilleP ${ }^{4}$ and FinetGM ${ }^{1,2}$ \\ ${ }^{1}$ Department of Interventional Cardiology, Cardiovascular Hospital, Hospices Civils de Lyon, Lyon, France \\ 2INSERM U1060 "CARMEN", Lyon, France \\ ${ }^{3}$ Department of Cardiac Valve Surgery, Cardiovascular Hospital, Hospices Civils de Lyon, Lyon, France \\ ${ }^{4}$ Department of Radiology, Cardiovascular Hospital, Hospices Civils de Lyon, Lyon, France
}

\begin{abstract}
Background: Transcatheter Aortic Valve Implantation (TAVI) is a therapeutic option for patients presenting with severe aortic stenosis and in whom surgery is contraindicated. Pre-procedural Pulmonary Hypertension (PH) has been shown to be a factor of poor prognosis in surgical and TAVI studies.
\end{abstract}

Aims: We sought to evaluate the clinical impact and prognostic implications of the presence of post-TAVI PH.

Methods: The outcome of post-TAVI Pulmonary Artery Systolic Pressure (PASP) was studied in 58 high-risk patients with severe symptomatic aortic stenosis, by assessing clinical presentation and prognosis and determining predictive factors.

Results: Post-TAVI PH (PASP $>40 \mathrm{mmHg}$ ) affected $43 \%$ of patients at 6 months. Despite excellent aortic results in both groups, patients with post-TAVI PH were more symptomatic, with were severer according to the New York Heart Association classification (class III or IV), higher cardiovascular mortality and more frequent readmission for cardiac failure. On univariate analysis, factors for elevated PASP were: female sex, history ofmyocardial infarction, pacemaker implantation and permanent pacing, atrial fibrillation, and degree of mitral regurgitation. On multivariate analysis, only atrial fibrillation remained an independent factor for post-TAVI PH.

Conclusion: $\mathrm{PH}$ is frequently present after TAVI and allows identification of a subgroup of patients with poorer clinical presentation and cardiovascular prognosis. Further studies and especially complementary myocardial investigation seem necessary.

Keywords: Aortic stenosis; Trans catheter aortic valve implantation; Pulmonary hypertension

Abbreviations: TAVI: Trans catheter Aortic Valve Implantation; PH: Pulmonary Hypertension; PASP: Pulmonary Artery Systolic Pressure; NYHA: New York Heart Association; BNP: Brain Natriuretic Peptide; LV: Left Ventricle; LVEF: Left Ventricle Ejection Fraction; STS Score: Society of Thoracic Surgeons Score; VARC 2: Valve Academic Research Consortium; MR: Mitral Regurgitation; AR: Aortic Regurgitation; ACE: Angiotensin-Converting-Enzyme

\section{Introduction}

Aortic stenosis is the most frequent valvular disease in the elderly population [1]. Since 2002, TAVI (Transcatheter Aortic Valve Implantation) has emerged as a therapeutic option for patients presenting with severe aortic stenosis in whichsurgery is contraindicated [2-4]. Pulmonary Hypertension $(\mathrm{PH})$ is frequently present in aortic stenosis 3 and its reduction has been shown after TAVI $[4,5]$. Its presence is known to be a factor of poor prognosis in aortic stenosis. Pre- and post-operative PH has been shown to be associated with reduced post-surgical survival6, and pre-procedural $\mathrm{PH}$ to be associated with higher post-TAVI mortality [5].

We sought to evaluate clinical impact and prognosis of postprocedural $\mathrm{PH}$ by identifying a subgroup of patients with high pulmonary pressure after TAVI and searching for its predictive factors. To our knowledge, this is the first study to measure the outcome of pulmonary pressures months after TAVI [6].

\section{Methods}

\section{Study population}

This study analyses prospectively all patients undergoing TAVI with a CorevalveTM device (Medtronic CV, Irvine, CA) in our center between November 2008 and December 2010. All presented with criteria for severe aortic stenosis as defined in the most recent recommendations and were symptomatic [7]. TAVI was indicated after evaluation of each medical situation by a multidisciplinary staff, after contraindicating surgical aortic valve replacement because of excessive perioperative risk. All patients gave written informed consent.

\section{Study design}

Baseline assessment: Initial assessment involved evaluation of clinical symptoms and NYHA (New York Heart Association) score,

*Corresponding author: Green Lisa, Department of Interventional Cardiology Cardiovascular Hospital, Hospices Civils de Lyon, Lyon, France, Tel: 00334723 57418; Fax: 00334723 57310; E-mail: lisa.green@dbmail.com

Received January 07, 2014; Accepted February 05, 2014; Published February 12,2014

Citation: Lisa G, Rioufol G, Vergnat M, Obadia JF, Saroul C, et al. (2014) Clinical Impact and Prognosis of Pulmonary Hypertension after Transcatheter Aortic Valve Implantation. J Cardiovasc Dis Diagn 2: 143. doi:10.4172/2329-9517.1000143

Copyright: ( 2014 Lisa G, et al. This is an open-access article distributed under the terms of the Creative Commons Attribution License, which permits unrestricted use, distribution, and reproduction in any medium, provided the original author and source are credited. 
EuroSCORE and STS score were calculated in order to estimate perioperative risk. Brain Natriuretic Protein levels (BNP, normal $<100$ $\mathrm{pg} / \mathrm{mL}$ ) were measured. Echocardiography was performed, with measurement of the usual aortic severity assessment parameters (indexed aortic valve area, mean aortic gradient, velocity ratio), Left Ventricle Ejection Fraction (LVEF), and grading of any other valvulopathy. LV diastolic function was assessed by measuring left atrial area, Doppler mitral flow velocity (E/A) and the ratio of mitral early diastolic flow velocity to tissue Doppler mitral annular lengthening velocity (E/E'). Pulmonary Artery Systolic Pressure (PASP) was calculated by adding trans tricuspid gradient to mean right atrial pressure. Trans tricuspid gradient was obtained from the maximum tricuspid regurgitation jet velocity in continuous-wave Doppler, and considered as equal to right ventricular systolic pressure in the absence of right ventricular obstruction [8,9]. Right atrial pressure was determined from the diameter of the inferior vena cava and its motion during respiration [5]. Echocardiographic evaluation of PASP is known to correlate strongly with catheterization measurement [10].

Pulmonary hypertension was defined as PASP $>40 \mathrm{mmHg}$, normal PASP being estimated at $336 \mathrm{mmHg}$ in a population of 90 year-olds [11].

TAVI procedures: The Corevalve TM self-expandable device (Medtronic CV, Irvine, CA), used in all patients, consists of a trileaflet porcine pericardial valve inside a self-expandable nitinol stent. Procedures were performed in a sterile catheterization laboratory. Standard balloon valvuloplasty was performed, then the bioprosthetic valve was inserted via the femoral artery; the subclavian artery was used if femoral access was impossible. A cardiac pacing catheter was systematically placed in the right ventricle via the femoral vein, and removed at the end of the procedure if no conduction anomaly was observed during procedure. Two different valve sizes were used (26 or $29 \mathrm{~mm}$ ), depending on the size of the native aortic annulus. The femoral arterial access was closed with a percutaneous closure system (or surgically for subclavian access). All patients received heparin during procedure and 6 months' post-procedural dual antiplatelet therapy. All major procedural adverse events were identified as recommended by VARC-28. Intracardiac electrophysiology study was performed systematically during the first week after TAVI implantation and a pacemaker was implanted in case of persistent serious conduction anomaly (left bundle branch block or HV period $>55 \mathrm{~ms}$ ).

\section{Follow-up}

All patients underwent systematic 1 and 6 month clinical assessment. Blood BNP level was measured at 1 month and complete echocardiography (as described for baseline assessment) was performed at 6 months. $\mathrm{PH}$ was again defined as PASP $>40 \mathrm{mmHg}$. Any episode of atrial fibrillation or need for new pacemaker was noted. Any readmission for cardiac failure or death (cardiovascular or noncardiovascular mortality as defined by VARC-28) was reported after 30 days. Prescribed medications were reported, including diuretics, betablockers and Angiotensin-Converting-Enzyme (ACE) inhibitors.

\section{Group identification}

Patients were divided into 2 groups according to PASP at 6 months post-TAVI: one group without $\mathrm{PH}(\mathrm{PASP} \leq 40 \mathrm{mmHg}$, considered as a favorable result) and the other with $\mathrm{PH}$ (PASP $>40 \mathrm{mmHg}$, considered as an unfavorable result).

\section{Statistical analysis}

Qualitative values were expressed as n (percentage) and quantitative values as mean \pm SD. Patient data were compared by Student's t-test for continuous variables and chi-squared test for categorical variables. A p-value of 0.05 was considered significant. Stepwise logistic regression analysis was performed, including all variables with $\mathrm{p}<0.05$ on univariate analysis, and determined predictive values for post-TAVI $\mathrm{PH}$. Mortality and survival rates were presented as Kaplan-Meier curves. Statistical analyses were performed with Stat View 5.0 software (SAS Institute Inc., Cary, NC).

\section{Results}

In total, 58 were studied during the inclusion period from November 2008 to December 2010.

Mean follow-up was $20 \pm 7$ months.

\section{Global results}

Patient data at baseline and follow-up, and the principal TAVI results and complications, are presented in Table 1. Missing data were only noted for BNP measures.

Patients presented high perioperative risk (mean EuroSCORE of $24 \% \pm 14$ and STS score of $8 \% \pm 7$ ) and were elderly ( $83 \pm 7$ years). Baseline echocardiography showed normal LVEF ( $57 \% \pm 10.3) ; 40 \%$ of patients presented $\mathrm{PH}$, as defined above, at inclusion.

TAVI was successful in $100 \%$ of patients; femoral access was used in $81 \%$ of procedures. Twenty six percent of patients showed conduction anomalies during TAVI, $7 \%$ major bleeding events, $2 \%$ pericardial tamponade and $7 \%$ stroke events.

Follow-up found overall clinical improvement, with significantly reduced NYHA scores. No significant results noted for BNP analysis.

Echocardiography showed excellent aortic results, with significantly reduced mean aortic gradient and increased indexed aortic valve area and velocity ratio. LVEF remained unchanged.

Absolute reduction concerning PASP values 6 months after TAVI was non-significant ( 45 to $42 \mathrm{mmHg}$ ) and $43 \%$ of patients presented criteria of $\mathrm{PH}$, as defined in Methods Section, 6 months after TAVI. More interestingly, individual PASP evolution patterns did not systematically consist of descending slopes, as might be expected, but remained elevated, or even increased in a certain number of cases (Figure 1).

The degree of Mitral Regurgitation (MR) significantly decreased. Aortic regurgitation did not significantly change, and was low-grade ( $\leq$ II) in $98 \%$ of cases.

Reduction in atrial fibrillation was non-significant (36 to 29\%). Pacemaker implantation was required in $45 \%$ of patients after TAVI, although only $14 \%$ needed permanent pacing.

There were 13 deaths (22\%) during follow-up, 54\% being due to cardiovascular causes. Twenty two percent of patients were readmitted for cardiac failure. Medical treatment was optimal.

\section{Analysis by 2 groups}

Patients were divided into 2 groups according to PASP values 6 months after TAVI. Results are presented in Table 2. Follow-up was identical in both groups.

PASP levels were similar before TAVI in both groups and higher after TAVI in the $\mathrm{PH}$ group ( 53 vs. $32 \mathrm{mmHg}$ ). 25 patients presented criteria for post-TAVI PH ( $43 \%$ of the total population): persistent $\mathrm{PH}$ in 14 cases and new onset in 11 cases. Four clinical situations can 
Citation: Lisa G, Rioufol G, Vergnat M, Obadia JF, Saroul C, et al. (2014) Clinical Impact and Prognosis of Pulmonary Hypertension after Transcatheter Aortic Valve Implantation. J Cardiovasc Dis Diagn 2: 143. doi:10.4172/2329-9517.1000143

Page 3 of 7

\begin{tabular}{|c|c|c|c|}
\hline & Baseline & $\begin{array}{c}6 \text { months after } \\
\text { TAVI }\end{array}$ & $\mathbf{p}$ \\
\hline \multicolumn{4}{|l|}{ Patient characteristics } \\
\hline Male/Female, $n$ & $29 / 29$ & & \\
\hline Age, y & $83 \pm 7$ & & \\
\hline Body Mass Index, kg/m² & $26 \pm 5$ & & \\
\hline Syncope & $10(17 \%)$ & & \\
\hline Angina & $17(29 \%)$ & & \\
\hline Hypertension & $40(69 \%)$ & & \\
\hline Diabetes mellitus & $15(26 \%)$ & & \\
\hline $\begin{array}{l}\text { Pulmonary chronic obstructive } \\
\text { disease }\end{array}$ & $13(22 \%)$ & & \\
\hline History of myocardial infarction & $9(16 \%)$ & & \\
\hline Hostile chest & $9(16 \%)$ & & \\
\hline History of coronary by-pass & $21(36 \%)$ & & \\
\hline EuroScore & $24 \pm 14$ & & \\
\hline STS score & $8 \pm 7$ & & \\
\hline Creatinine clearance, $\mathrm{mL} / \mathrm{min}$ & $59 \pm 21$ & & \\
\hline NYHA I/II/III/IV & $3 / 17 / 27 / 11$ & 23/18/10/7 & $<0.0001$ \\
\hline Atrial fibrillation & $21(36 \%)$ & $17(29 \%)$ & 0.21 \\
\hline Pacemaker & $7(12 \%)$ & $33(57 \%)$ & $<0.0001$ \\
\hline $\mathrm{BNP}, \mathrm{pg} / \mathrm{mL}$ & $\begin{array}{c}1448 \pm 2098 \\
(n=32)\end{array}$ & $\begin{array}{c}708 \pm 1208 \\
(n=42)\end{array}$ & 0.06 \\
\hline \multicolumn{4}{|l|}{ Echocardiography } \\
\hline LVEF & $57 \pm 10$ & $58 \pm 12$ & 0.68 \\
\hline Mean aortic gradient, $\mathrm{mmHg}$ & $48 \pm 17$ & $8 \pm 4$ & $<0.0001$ \\
\hline Velocity ratio & $0.21 \pm 0.05$ & $0.6 \pm 0.2$ & $<0.0001$ \\
\hline Indexed $/ 2 \mathrm{~m}^{2}$ aortic valve area, $\mathrm{cm}$ & $0.41 \pm 0.09$ & $1.07 \pm 0.38$ & $<0.0001$ \\
\hline Mitral regurgitation grade 0/I/II/III/IV & $7 / 30 / 21 / 0 / 0$ & $13 / 26 / 16 / 3 / 0$ & 0.047 \\
\hline PASP, $\mathrm{mmHg}$ & $45 \pm 16$ & $42 \pm 14$ & 0.3 \\
\hline $\begin{array}{l}\text { Pulmonary Hypertension } \\
\text { (PASP }>40 \mathrm{mmg} \text { ) }\end{array}$ & $23(40 \%)$ & $25(43 \%)$ & 0.59 \\
\hline Aortic regurgitation grade $0 / \mathrm{I} / \mathrm{II} / \mathrm{III} / \mathrm{IV}$ & $10 / 36 / 11 / 1 / 1$ & $15 / 32 / 10 / 1 / 0$ & 0.40 \\
\hline Aortic VTI, cm & $21 \pm 10$ & $21 \pm 5$ & 0.52 \\
\hline \multicolumn{4}{|c|}{$\begin{array}{l}\text { TAVI results and complications during follow- } \\
\text { up }\end{array}$} \\
\hline Follow-up, m & & $20 \pm 7$ & \\
\hline TAVI Success & & $58(100 \%)$ & \\
\hline Femoral access & & $47(81 \%)$ & \\
\hline Sub-clavian access & & $11(19 \%)$ & \\
\hline Conduction abnormalities & & $15(26 \%)$ & \\
\hline Severe bleeding & & $4(7 \%)$ & \\
\hline Pericardial tamponade & & $1(2 \%)$ & \\
\hline Stroke & & $4(7 \%)$ & \\
\hline Mortality any cause & & $13(22 \%)$ & \\
\hline Cardiovascular mortality & & $7(12 \%)$ & \\
\hline Hospitalisation for cardiac failure & & $13(22 \%)$ & \\
\hline \multicolumn{4}{|l|}{ Medications } \\
\hline Diuretics & $38(65 \%)$ & $50(86 \%)$ & 0.0079 \\
\hline ACE Inhibitors & $31(54 \%)$ & $33(57 \%)$ & 0.74 \\
\hline Beta Blockers & $20(35 \%)$ & $27(47 \%)$ & 0.23 \\
\hline
\end{tabular}

Table 1: Patient characteristics at baseline and 6 months after TAVI, TAVI results and complications.

be identified by analyzing presence or absence of $\mathrm{PH}$ before and after TAVI Table 3.

Baseline characteristics were similar for age, history of chronic obstructive pulmonary disease and pre-operative severity (EuroSCORE and STS score). Patients with PH were significantly more often female and more frequently had history of myocardial infarction. Baseline LVEF was similar in both groups (56 and 58\% respectively). Patients with $\mathrm{PH}$ were significantly more symptomatic.

Echocardiographic findings were similar, with excellent results on the aortic valve and LVEF. Elevated PASP levels were consistent with LV diastolic dysfunction (significantly higher left atrial area before and after TAVI, E/A and E/E' ratios could be interpreted in two-thirds of patients and appeared consistent with elevated diastolic LV pressures after TAVI; E/A higher than 2 or E/E' higher than 15).

Mitral regurgitation was significantly more severe both before and after TAVI in the PH group, with post-TAVI MR grade III in 3 cases, and its evolution was more often unfavorable (36\% worsened, $36 \%$ unchanged and $28 \%$ improved in the $\mathrm{PH}$ group, versus $21 \%, 49 \%$ and $30 \%$ respectively in the non-PH group). Atrial fibrillation was significantly more frequent in the PH group at baseline (56\% vs. $21 \%$ ) and post-TAVI ( $48 \%$ vs. $15 \%)$. Pacemakers were significantly more frequent in the PH group both before (20\% vs. $6 \%$ ) and after TAVI ( $72 \%$ vs. $45 \%$ ), with more frequent permanent pacing (20\% vs. $9 \%)$. Stepwise logistic regression applied to the variables identified as significant on univariate analysis showed that pre-TAVI atrial fibrillation was the only independent predictive factor for post-TAVI PH $(\mathrm{p}=0.006)$.

Proportions of the predictive factors identified after univariate analysis were measured for each of the 4 clinical situations and presented in Table 3; due to the small number of patients in each group, no statistic significance could be calculated. However descriptive analysis can be performed and atrial fibrillation appears more frequent in the group with persisting $\mathrm{PH}$, and post-TAVI MR was more severe in the group with new-onset $\mathrm{PH}$.

Figure 2 shows the Kaplan-Meier curves for overall and cardiovascular survival. Mortality from any cause was similar in both groups (24\% and $21 \%$ for the groups with and without $\mathrm{PH}$, respectively); however, deaths in the $\mathrm{PH}$ group were exclusively from cardiovascular causes, and cardiovascular mortality was therefore significantly higher in that group ( $24 \%$ versus $3 \%$ ) and cardiovascular survival significantly poorer (76\% versus $97 \%$ at 3 years). Non-cardiovascular deaths in the non- $\mathrm{PH}$ group were due to terminal cancer in nearly half of the cases

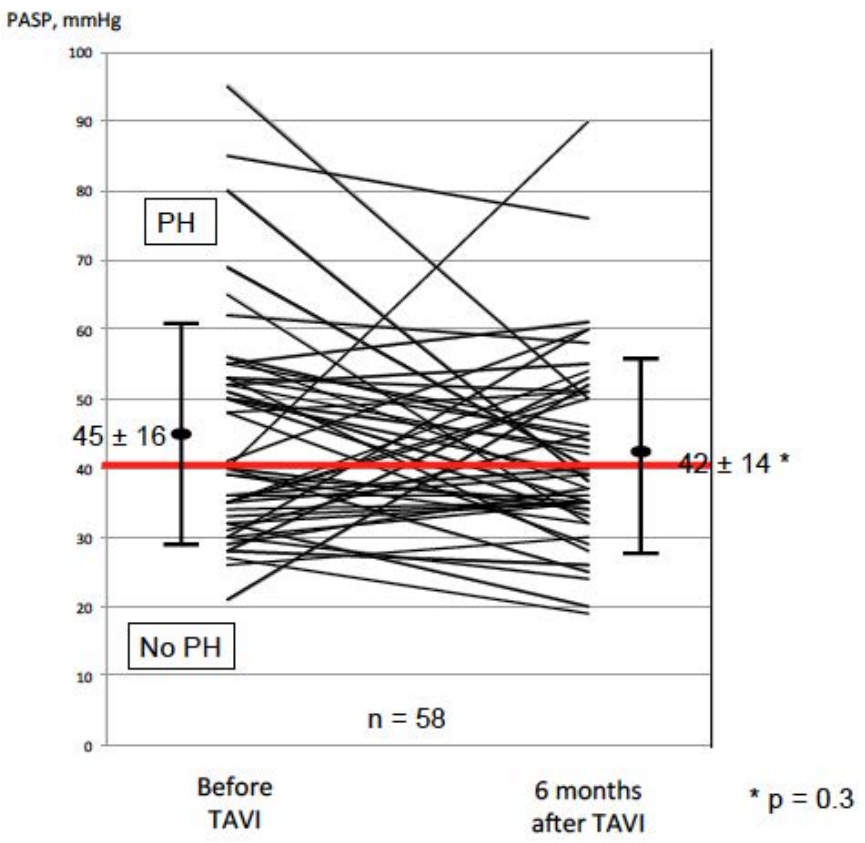

Figure 1: Outcome of Pulmonary Arterial Systolic Pressures before and 6 months after TAVI. 
Citation: Lisa G, Rioufol G, Vergnat M, Obadia JF, Saroul C, et al. (2014) Clinical Impact and Prognosis of Pulmonary Hypertension after Transcatheter Aortic Valve Implantation. J Cardiovasc Dis Diagn 2: 143. doi:10.4172/2329-9517.1000143

Page 4 of 7

\begin{tabular}{|c|c|c|c|}
\hline & $\begin{array}{c}\text { Group } \\
\text { without PH at } \\
6 \mathrm{M}\end{array}$ & $\begin{array}{l}\text { Group with } \\
\mathrm{PH} \text { at } 6 \mathrm{M}\end{array}$ & $\mathbf{p}$ \\
\hline \multicolumn{4}{|l|}{ Patient characteristics } \\
\hline Distribution in TAVI population & $33(57 \%)$ & $25(43 \%)$ & \multirow{2}{*}{$\overline{-}$} \\
\hline Follow-up & $20 \pm 7$ & $20 \pm 8$ & \\
\hline Male/Female & $18 / 15$ & $11 / 14$ & 0.03 \\
\hline Age, y & $83 \pm 7$ & $82 \pm 7$ & 0.62 \\
\hline Hypertension & $23(70 \%)$ & $17(68 \%)$ & 0.06 \\
\hline Diabetes & $9(27 \%)$ & $6(24 \%)$ & 0.03 \\
\hline $\begin{array}{l}\text { Pulmonary chronic obstructive } \\
\text { disease }\end{array}$ & $7(21 \%)$ & $6(24 \%)$ & 0.07 \\
\hline History of myocardial infarction & $4(12 \%)$ & $5(20 \%)$ & 0.02 \\
\hline History of coronary by-pass & $14(42 \%)$ & $7(28 \%)$ & 0.007 \\
\hline EuroScore & $23 \pm 12$ & $25 \pm 6$ & 0.73 \\
\hline STS score & $8 \pm 8$ & $7 \pm 5$ & 0.19 \\
\hline Creatinine clearance, $\mathrm{mL} / \mathrm{min}$ & $59 \pm 23$ & $60 \pm 18$ & 0.38 \\
\hline NYHA at baseline I/II/III/IV & $2 / 11 / 13 / 7$ & $1 / 6 / 14 / 4$ & 0.01 \\
\hline NYHA after TAVI I/II/III/IV & $19 / 9 / 4 / 1$ & $4 / 9 / 6 / 6$ & $<0.0001$ \\
\hline Atrial fibrillation at baseline & $12(21 \%)$ & $14(56 \%)$ & $<0.0001$ \\
\hline Atrial fibrillation after TAVI & $5(15 \%)$ & $12(48 \%)$ & $<0.0001$ \\
\hline Pacemaker at baseline & $2(6 \%)$ & $5(20 \%)$ & 0.002 \\
\hline Pacemaker after TAVI & $5(15 \%)$ & $18(72 \%)$ & $<0.0001$ \\
\hline Echocardiography & \multirow{2}{*}{$56 \pm 11$} & \multirow{2}{*}{$58 \pm 10$} & \multirow{2}{*}{0.5} \\
\hline LVEF at baseline & & & \\
\hline LVEF after TAVI & $58 \pm 11$ & $58 \pm 14$ & 0.94 \\
\hline $\begin{array}{l}\text { Indexed }{ }^{2} / \mathrm{m}^{2} \text { aortic valve area after } \\
\text { TAVI, cm }\end{array}$ & $1.07 \pm 0.4$ & $0.98 \pm 0.34$ & 0.22 \\
\hline Velocity ratio after TAVI & $0.57 \pm 0.15$ & $0.56 \pm 0.22$ & 0.17 \\
\hline Mean gradient after TAVI, mmHg & $9 \pm 5$ & $7 \pm 3$ & 0.1 \\
\hline $\begin{array}{l}\text { Aortic regurgitation grade after TAVI, } \\
\text { O/I/II/III/IV }\end{array}$ & $8 / 18 / 6 / 1 / 0$ & $7 / 14 / 4 / 0 / 0$ & 0.37 \\
\hline $\begin{array}{l}\text { Mitral regurgitation grade at } \\
\text { baseline, 0/I/II/III/IV }\end{array}$ & $4 / 21 / 8 / 0 / 0$ & $3 / 10 / 12 / 0 / 0$ & 0.001 \\
\hline \multirow{2}{*}{$\begin{array}{l}\text { Mitral regurgitation grade after TAVI, } \\
\text { 0/I/II/III/IV }\end{array}$} & $7 / 18 / 8 / 0 / 0$ & $6 / 8 / 8 / 3 / 0$ & 0.001 \\
\hline & \multirow{2}{*}{$42 \pm 13$} & \multirow{2}{*}{$48 \pm 18$} & \multirow{2}{*}{0.17} \\
\hline PASP at baseline, $\mathrm{mmHg}$ & & & \\
\hline PASP after TAVI, mmHg & $32 \pm 6$ & $53 \pm 11$ & $<0.0001$ \\
\hline Left atrial $^{2}$ area at baseline, $\mathrm{mm}$ & $25 \pm 6$ & $29 \pm 9$ & 0.02 \\
\hline Left atrial $^{2}$ area after TAVI, mm & $23 \pm 5$ & $30 \pm 8$ & $<0.0001$ \\
\hline \multicolumn{4}{|c|}{ TAVI results and complications during follow-up } \\
\hline Mortality any cause & $7(21 \%)$ & $6(24 \%)$ & 0.10 \\
\hline Cardiovascular mortality & $1(3 \%)$ & $6(24 \%)$ & 0.015 \\
\hline Hospitalisation for cardiac failure & $5(15 \%)$ & $8(32 \%)$ & 0.005 \\
\hline \multicolumn{4}{|l|}{ Medications } \\
\hline Diurectics & $25(76 \%)$ & $25(100 \%)$ & 0.005 \\
\hline ACE inhibitors & $16(48 \%)$ & $17(68 \%)$ & 0.006 \\
\hline Beta blockers & $13(39 \%)$ & $14(56 \%)$ & 0.001 \\
\hline
\end{tabular}

Table 2: Patient characteristics and outcomes depending on the presence or absence of Pulmonary Hypertension 6 months after TAVI.

( $43 \%$ of non-cardiovascular deaths), the others being essentially due to septic causes remote from the TAVI procedure. Therefore, noncardiovascular deaths due to cancer in the non- $\mathrm{PH}$ group might have been avoided by a better patient selection before TAVI and should not impair the significance of greater cardiovascular mortality found in the $\mathrm{PH}$ group. Moreover, patients presenting post-TAVI $\mathrm{PH}$ were significantly more frequently admitted for cardiac failure (32\%), although they were effectively treated and received significantly more medication (100\% diuretics, $68 \%$ ACE inhibitors and 56\% betablockers).

\section{Discussion}

\section{Outcome of PH after TAVI}

Pulmonary hypertension is frequently associated with aortic stenosis. Frequency is quite variable in the literature, as the definition of PH differs from one study to another. The present series showed a $40 \%$ rate of $\mathrm{PH}$ at baseline, which is similar to the results of the PARTNER trial 3. Baseline $\mathrm{PH}$ was more frequent in a recent trial comparing evolution between surgery, TAVI and balloon valvuloplasty 5 , at $68.2 \%$ (for PASP $>40 \mathrm{mmHg}$ ); this can be explained by the specific design of that study (groups matched for baseline PASP). In the present study, the reduction in pulmonary pressure after TAVI was non-significant (from 45 to $42 \mathrm{mmHg}$ ); this could be explained by lower baseline PASP in our study (mean $45 \mathrm{mmHg}$ ). Significant decrease in PASP was reported in recent TAVI trials 4-5: from $66.1 \mathrm{mmHg}$ at 1 week to 44.8 $\mathrm{mmHg}$ at 12 months 5 . The present study modulates conveys a nuance to these results, with presence of $\mathrm{PH}$ in $43 \%$ of patients at 6 months; moreover, $\mathrm{PH}$ persisted in 14 cases and was new in 11 cases. To our knowledge, no other study has developed this fact.

\section{Clinical implications and prognosis of PH after TAVI}

The present overall mortality rates were similar to those of the PARTNER trial 3, where 1-year mortality from any cause was $30.7 \%$, and $20.5 \%$ for cardiovascular causes. Pre-procedural PH was reported to be a factor of poor prognosis in aortic stenosis, in surgical series6 and a recent TAVI trial5. The present findings complete these results, with poorer prognosis in case of PH after TAVI. To our knowledge, this point was not developed in previous studies. While mortality from all causes did not significantly differ between groups, cardiovascular mortality was higher in the $\mathrm{PH}$ group. More interestingly, medium

\begin{tabular}{|c|c|c|c|c|}
\hline & $\begin{array}{l}\text { No pulmonary } \\
\text { hypertension }\end{array}$ & $\begin{array}{c}\text { Improving } \\
\text { pulmonary } \\
\text { hypertension }\end{array}$ & $\begin{array}{l}\text { New pulmonary } \\
\text { hypertension }\end{array}$ & $\begin{array}{c}\text { Persisting } \\
\text { pulmonary } \\
\text { hypertension }\end{array}$ \\
\hline$n$ & 23 & 10 & 11 & 14 \\
\hline $\begin{array}{l}\text { History of } \\
\text { myocardial } \\
\text { infarction, \% (n) } \\
\text { LVEF > 50\%, } \\
\%(n)\end{array}$ & $13(3)$ & $10(1)$ & $18(2)$ & $21(3)$ \\
\hline $\begin{array}{l}\text { LVEF > 50\%, } \\
\%(n)\end{array}$ & 78 (18) & $50(5)$ & $73(8)$ & $71(10)$ \\
\hline $\begin{array}{l}30<\text { LVEF }<50 \% \\
\%(n)\end{array}$ & $22(5)$ & $50(5)$ & $27(3)$ & $29(4)$ \\
\hline $\begin{array}{l}\text { Pacemaker } \\
\text { after TAVI, } \\
\%(\mathrm{n})\end{array}$ & $39(9)$ & $60(6)$ & $73(8)$ & $71(10)$ \\
\hline $\begin{array}{l}\text { PM } \\
\text { dependancy, } \\
\%(n)\end{array}$ & $4(1)$ & $20(2)$ & $18(2)$ & $21(3)$ \\
\hline $\begin{array}{l}\text { Baseline atrial } \\
\text { fibrillation, \% (n) }\end{array}$ & $9(2)$ & $50(5)$ & $55(6)$ & $57(8)$ \\
\hline $\begin{array}{l}\text { Atrial fibrillation } \\
\text { after TAVI, } \\
\%(n)\end{array}$ & $9(2)$ & $30(3)$ & $36(4)$ & $57(8)$ \\
\hline $\begin{array}{l}\text { Baseline mitral } \\
\text { insufficiency } 0 / / / \\
\text { II/III/IV, n }\end{array}$ & $4 / 16 / 3 / 0 / 0$ & $0 / 5 / 5 / 0 / 0$ & $0 / 4 / 7 / 0 / 0$ & $3 / 6 / 5 / 0 / 0$ \\
\hline $\begin{array}{l}\text { Mitral } \\
\text { insufficiency } \\
\text { after TAVI 0/I/II/ } \\
\text { III/IV, n }\end{array}$ & $6 / 12 / 5 / 0 / 0$ & $1 / 6 / 3 / 0 / 0$ & $3 / 2 / 3 / 3 / 0$ & $3 / 6 / 5 / 0 / 0$ \\
\hline
\end{tabular}

Table 3: Distribution of predictive factors for Pulmonary Hypertension. 

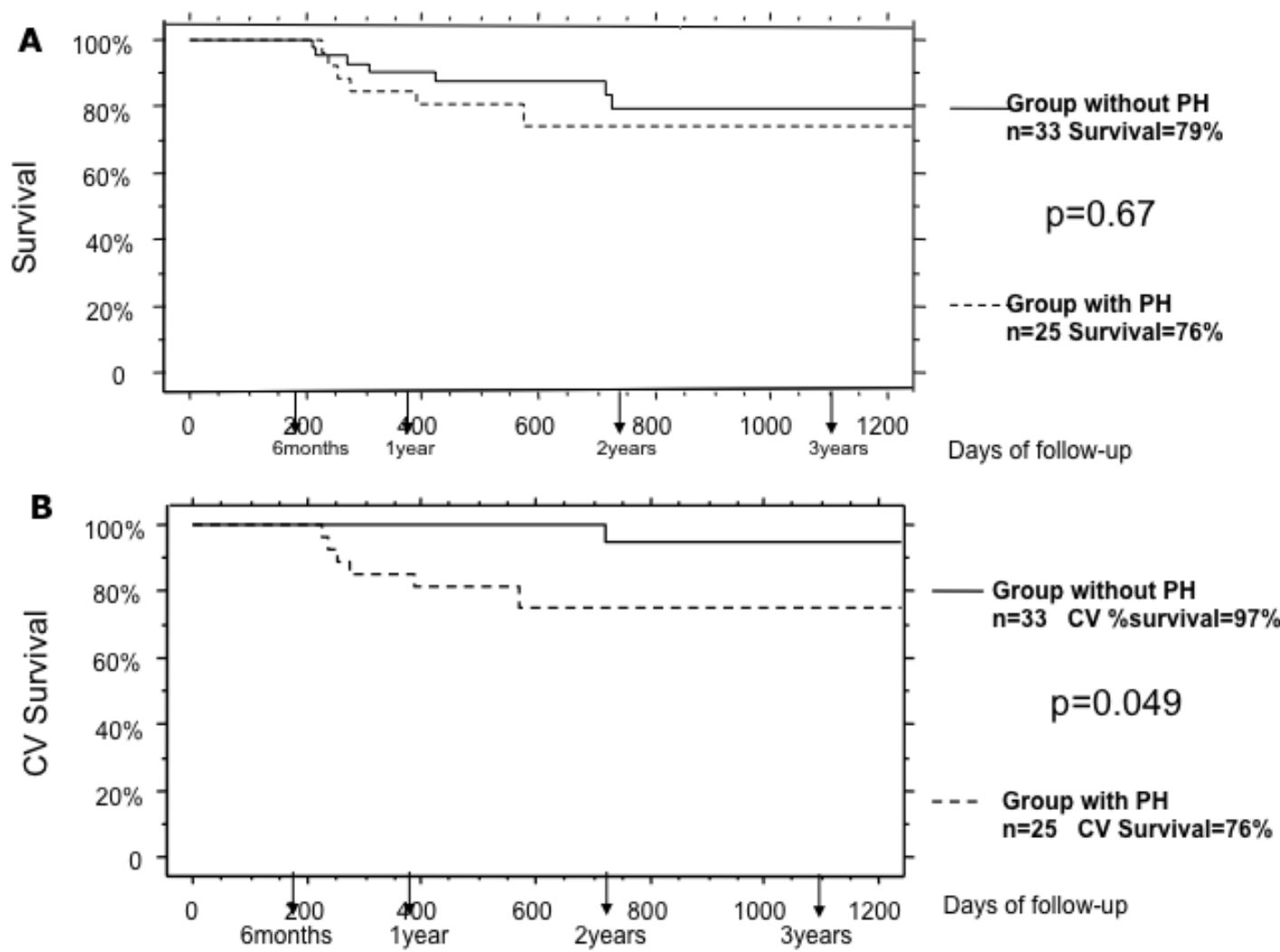

Figure 2: Kaplan-Meier curves for survival (A) and cardiovascular survival (B).

term mortality (past the 30 first days) is usually strongly determined by non-cardiac deaths, especially from respiratory causes [12]. Patients in the PH group died exclusively from cardiac causes (24\% mortality rate). Moreover, clinical evolution was less favorable, as these patients were more symptomatic, with more frequent admission for cardiac failure and more intensive medical treatment during follow-up. BNP levels did not differ significantly between groups; this is explained by the small number of samples performed. It is difficult to predict the risk for post-TAVI PH in order to better select patients before TAVI. Indeed, the only predictive factor seems to be pre-TAVI atrial fibrillation. Moreover, prognosis was shown to be improved in the subgroup of patients with post-TAVI $\mathrm{PH}$, when comparing surgical to medical treatment at 1 monthand 5 years $[13,14]$. In the PARTNER trial3, TAVI provided better results than medical treatment in all groups, including in the $\mathrm{PH}$ group. These patients should therefore be surveyed even more closely than usual for signs of cardiac failure, and should receive intensified medical treatment: i.e., diuretics, ACE inhibitors and beta blockers.

\section{Predictive factors for post-TAVI PH}

Aortic results and LV systolic function: These elements cannot explain the elevation of pulmonary pressure, as results on the aortic valve were excellent and post-TAVI LVEF was normal and stable. Results were similar to those in recent trials 2-4and similar in both groups.

History of myocardial infarction: Although myocardial infarction was more frequent in the $\mathrm{PH}$ group, systolic dysfunction cannot explain the elevation of PASP, as LVEF was normal in both groups.
Myocardial scarring, however, could induce diastolic dysfunction and elevate pulmonary pressure [15].

Pacemaker implantation: Pacemakers are more often required after Corevalve TM implantation (Medtronic CV, Irvine, CA,), possibly due to deeper prosthetic valve insertion beyond the non-coronary cusp [16]. The present rate of pacemaker implantation, however, was higher than usual in the literature 4 , at $45 \%$ of cases after TAVI (compared to $25 \%$ in the FRANCE registry); this can be explained by the protocol applied in our center during this study (described in the Method section). This approach was not associated with higher postoperative mortality or morbidity. However, pacemaker presence was significantly more frequent in the $\mathrm{PH}$ group. A ventricular pacing effect on LV diastolic pressure is questionable, as long-term ventricular pacing was found to be associated with reduced LV systolic function and impaired relaxation [17]. However, indications for pacemaker were generally transitory conduction abnormalities (pacemaker dependency was low, at 9-20\%); ventricular desynchronisation therefore seems unlikely. Moreover no significant traumatic tricuspid regurgitation was noted.

Mitral regurgitation: MR was significantly more severe in the $\mathrm{PH}$ group. It is known to be associated with aortic stenosis in two thirds of patients, with $27-48 \%$ moderate-to-severe MR in patients undergoing TAVI [18]. The present study found a $36 \%$ rate of pre-TAVI MR of grade 2 or more. Several studies addressed change in MR after TAVI [19]. Functional MR is expected to regress after TAVI but prosthetic valve implantation, especially with CorevalveTM (Medtronic CV, Irvine, CA), has been suspected of inducing MR by affecting the left ventricular outflow track because of its deep insertion under the aortic annulus or by impacting anterior mitral leaflet motion. Results are 
controversial: no correlation was found by Tzikas, with a mean insertion depth of $8 \mathrm{~mm}$; in contrast, a more recent study found a significant association between the depth of the aortic prosthesis $(7.6 \mathrm{~mm}$ versus $9.4 \mathrm{~mm}$ for the mean distance between the ventricular end and right coronary cusp) and aggravated MR [20,21]. In the present study, close examination of insertion depth revealed no correlation, especially for the 3 patients presenting severe MR (grade 3) (results not developed).

Atrial fibrillation: Atrial fibrillation at baseline and during followup was significantly more frequent in the $\mathrm{PH}$ group. Moreover, preTAVI atrial fibrillation emerged as an independent predictive factor for post-TAVI PH. Although rapid atrial fibrillation can be a cause of LV dysfunction, atrial fibrillation as such is more often a consequence [22]. Presence and severity of diastolic dysfunction were shown to be independently predictive of primary non-valvular atrial fibrillation in the elderly [23]. Greater prevalence of atrial fibrillation in the $\mathrm{PH}$ group therefore reflects the greater severity of LV diastolic dysfunction in these patients. The substrate for atrial fibrillation has been shown to be atrial fibrosis; myocardial investigation might therefore prove interesting, to explore the relevance of myocardial fibrosis [24].

Diastolic dysfunction: Echocardiographic evaluation of $\mathrm{LV}$ diastolic function was difficult in this population and limited by a certain number of comorbidities (atrial fibrillation, pacemaker implantation, calcifications extending to the mitral annulus). However, results were consistent with high LV diastolic pressure in the $\mathrm{PH}$ group. Myocardial fibrosis (due to a necrotic scar or to age) could possibly explain this diastolic dysfunction and elevated pulmonary pressures.

Differentiating new $\mathrm{PH}$ and persisting $\mathrm{PH}$ ?: Table 3, analyzing the 4 clinical situations identified by presence or absence of $\mathrm{PH}$ before and after TAVI, shows equivalent proportions of predictive factors from univariate analysis, especially when comparing the clinical situations of new or persisting $\mathrm{PH}$ and improving PH after TAVI. Numbers in each group are small; however post-TAVI MR appears more severe in the new $\mathrm{PH}$ group and post-TAVI atrial fibrillation more frequent in the persistent $\mathrm{PH}$ group, both results probably reflecting greater LV diastolic dysfunction.

Myocardial fibrosis?: Several recent studies measured myocardial fibrosis in this specific population, showing that its presence (identified by late gadolinium enhancement on myocardial MRI) was associated with reduced postoperative survival and its absence with significant postoperative improvement in LVEF and NYHA score [25,26]. Complementary myocardial exploration would therefore be interesting in this population in order to explore the implication of diastolic dysfunction in post-TAVI PH.

Study limitations: The present study was limited by the relatively small number of cases, in a population of elderly and complex patients with multiple comorbidities. However, it reflects the reality of the patient population presently treated by TAVI.

\section{Conclusion}

In conclusion, $\mathrm{PH}$ is frequently present after TAVI and is associated with poorer clinical status and cardiovascular prognosis. Clinicians should be aware of this possible evolution, in order to monitor patients even more closely and intensify post-procedural medical treatment. A certain number of predictive factors were significantly associated with elevation of pulmonary pressure, but only atrial fibrillation was identified as an independent predictive factor on multivariate analysis. These results are specific to the complex population of patients currently treated by TAVI; further studies are necessary, and especially complementary myocardial investigation to explore myocardial fibrosis.

\section{References}

1. lung B, Baron G, Butchart EG, Delahaye F, Gohlke-Bärwolf C, et al. (2003) A prospective survey of patients with valvular heart disease in Europe: The Euro Heart Survey on Valvular Heart Disease. Eur Heart J 24: 1231-1243.

2. Webb JG, Altwegg L, Boone RH, Cheung A, Ye J, et al. (2009) Transcatheter aortic valve implantation: impact on clinical and valve-related outcomes. Circulation 119: 3009-3016.

3. Leon MB, Smith CR, Mack M, Miller DC, Moses JW et al. (2010)Transcathete aortic-valve implantation for aortic stenosis in patients who cannot undergo surgery. N Engl J Med 363:1597-1607.

4. Eltchaninoff H, Prat A, Gilard M, Leguerrier A, Blanchard D, et al. (2011) Transcatheter aortic valve implantation: early results of the FRANCE (FRench Aortic National CoreValve and Edwards) registry. Eur Heart J 32: 191-197.

5. Ben-Dor I, Goldstein SA, Pichard AD, Satler LF, Maluenda G, et al. (2011) Clinical profile, prognostic implication, and response to treatment of pulmonary hypertension in patients with severe aortic stenosis. Am J Cardio I107:10461051.

6. Melby SJ, Moon MR, Lindman BR, Bailey MS, Hill LL, et al. (2011) Impact of pulmonary hypertension on outcomes after aortic valve replacement for aortic valve stenosis. J Thorac Cardiovasc Surg 141: 1424-1430.

7. Vahanian A, Otto CM (2010) Risk stratification of patients with aortic stenosis Eur Heart J 31: 416-423.

8. Kappetein AP, Head SJ, Généreux P, Piazza N, van Mieghem NM, et al (2012) Updated standardized endpoint definitions for transcatheter aortic valve implantation: The Valve Academic Research Consortium-2 consensus document. Eur J Cardiothorac Surg 42:45-60.

9. Currie PJ, Seward JB, Chan KL, Fyfe DA, Hagler DJ, et al. (1985) Continuous wave Doppler determination of right ventricular pressure: a simultaneous Doppler-catheterization study in 127 patients. J Am Coll Cardiol 6: 750-756.

10. Yock PG, Popp RL (1984) Noninvasive estimation of right ventricular systolic pressure by Doppler ultrasound in patients with tricuspid regurgitation. Circulation 70: 657-662.

11. Dokainish H, Gin K, Lee PK, Jue J (2003) Left ventricular filling patterns and pulmonary artery pressures in patients aged 90 to 100 years with normal echocardiography results. J Am Soc Echocardiogr 16: 664-669.

12. Rodés-Cabau J, Webb JG, Cheung A, Ye J, Dumont E, et al. (2010) Transcatheter aortic valve implantation for the treatment of severe symptomatic aortic stenosis in patients at very high or prohibitive surgical risk: acute and late outcomes of the multicenter Canadian experience. J Am Coll Cardiol 55: 1080-1090.

13. Cam A, Goel SS, Agarwal S, Menon V, Svensson LG, et al. (2011) Prognostic implications of pulmonary hypertension in patients with severe aortic stenosis. J Thorac Cardiovasc Surg 142: 800-808.

14. Pai RG, Varadarajan P, Kapoor N, Bansal RC (2007) Aortic valve replacement improves survival in severe aortic stenosis associated with severe pulmonary hypertension. Ann Thorac Surg 84: 80-85.

15. Pfeffer MA, Braunwald E (1990) Ventricular remodeling after myocardia infarction. Experimental observations and clinical implications. Circulation 81: 1161-1172.

16. Piazza N, Onuma Y, Jesserun E, Kint PP, Maugenest AM, et al. (2008) Early and persistent intraventricular conduction abnormalities and requirements for pacemaking after percutaneous replacement of the aortic valve. JACC Cardiovasc Interv 1: 310-316.

17. Chiladakis JA, Koutsogiannis N, Kalogeropoulos A, Alexopoulos D (2007) Long-term effects of atrial synchronous ventricular pacing on systolic and diastolic ventricular function in patients with normal left ventricular ejection fraction. Cardiology 108: 290-296

18. Cribier A, Eltchaninoff H, Bash A, Borenstein N, Tron C, et al. (2002) Percutaneous transcatheter implantation of an aortic valve prosthesis fo calcific aortic stenosis: first human case description. Circulation 106: 30063008

19. Cribier A, Eltchaninoff H, Tron C, Bauer F, Agatiello C, et al. (2006) Treatment 
Citation: Lisa G, Rioufol G, Vergnat M, Obadia JF, Saroul C, et al. (2014) Clinical Impact and Prognosis of Pulmonary Hypertension after Transcatheter Aortic Valve Implantation. J Cardiovasc Dis Diagn 2: 143. doi:10.4172/2329-9517.1000143

of calcific aortic stenosis with the percutaneous heart valve: mid-term follow-up from the initial feasibility studies: the French experience. J Am Coll Cardiol 47 1214-1223.

20. Tzikas A, Piazza N, Van Dalen BM, Schultz C, Geleijnse ML, et al. (2010) Changes in mitral regurgitation after transcatheter aortic valve implantation. Catheter Cardiovasc Interv75:43-49.

21. De Chiara B, Moreo A, De Marco F, Musca F, Oreglia J, et al. (2011) Influence of corevalverevalving system implantation on mitral valve function: An Echocardiographic Study in Selected Patients. Catheter Cardiovasc Interv 78: 638-644.

22. Grogan M, Smith HC, Gersh BJ, Wood DL (1992) Left ventricular dysfunction due to atrial fibrillation in patients initially believed to have idiopathic dilated cardiomyopathy. Am J Cardiol 69: 1570-1573.
23. Tsang TS, Gersh BJ, Appleton CP, Tajik AJ, Barnes ME, et al. (2002) Left ventricular diastolic dysfunction as a predictor of the first diagnosed nonvalvular atrial fibrillation in 840 elderly men and women. J Am Coll Cardiol 40: 16361644.

24. Burstein B, Nattel S (2008) Atrial fibrosis: mechanisms and clinical relevance in atrial fibrillation. J Am Coll Cardiol 51: 802-809.

25. Azevedo CF, Nigri M, Higuchi ML, Pomerantzeff PM, Spina GS, et al. (2010) Prognostic significance of myocardial fibrosis quantification by histopathology and magnetic resonance imaging in patients with severe aortic valve disease. J Am Coll Cardiol 56: 278-287.

26. Weidemann F, Herrmann S, Störk S, Niemann M, Frantz S, et al. (2009) Impact of myocardial fibrosis in patients with symptomatic severe aortic stenosis. Circulation 120:577-584 